\title{
Uptake and Impact of priority setting exercises in nutrition research publications
}

Dana Hawwash1, Wim Pinxten2, Jessica E. Raneri1, Patrick Kolsteren1, Carl Lachat1,*

1 Department of Food Technology, Safety and Health, Ghent University, Ghent, Belgium;

2 Faculty of Medicine and Life Sciences, Hasselt University, Hasselt, Belgium

Corresponding author: Carl Lachat, Ghent University, Department of Food Technology, Safety and Health, Coupure links 653, 9000 Gent-Belgium, +32 9264 9377, carl.lachat@ugent.be

\section{Short title: priority settings in nutrition research}

Acknowledgements: Antonio Sanna for producing the figure in high quality using Adopt illustrator cc, Joseph Millum, Ph.D., M.Sc. for reviewing and providing feedback.

Financial Support: There was no outside funding for this study. DH is supported by the special research fund (BOF) from Ghent University.

Conflict of Interest: None.

Authorship: Conceptualization: CL DH WP. Supervision: CL, WP. Wrote the first draft of the manuscript: DH. Contributed to the writing of the manuscript: CL JER WP PK. Analysis: DH JER. Agree with the study design, and findings: DH JER WP CL PK. All authors have read, and confirm that they meet ICMJE criteria for authorship.

Ethical Standards Disclosure: This study was conducted according to the guidelines laid down in the Declaration of Helsinki. Authors were asked to return an informed consent declaration by email. In accordance to Belgian Law, the questionnaire did not need clearance from an ethics committee. 


\begin{abstract}
Objective: To assess how priority setting exercises for nutrition research are considered in publication.
\end{abstract}

Design: Cross sectional design.

Settings: First, a citation analysis of priority setting exercises found in nutrition research until 2019 was conducted. The reasons for citation were extracted from the text of citing papers and the reasons were defined as: i) acting on the research questions identified as priorities, ii) acknowledging the priority setting exercise, iii) using the same method, or iv) previous knowledge to support evidence. Second, a survey with authors of the priority setting exercises was done to understand priority setters' perspectives on the impact and satisfaction of their work.

Participants: 21 priority setting exercise papers were included. 434 citing papers were found, of which 338 were considered in the citation analysis. A sample of 17 authors representing 13 priority setting exercise papers completed the impact and satisfaction survey.

Results: Half of the priority setting exercise papers were published by 2013. After excluding self-citations $(n=60)$, the priority setting papers had on average 18 citations. Priority setting exercises had a median of $1(\mathrm{IQR}=0-1)$ citing manuscript that acted on the recommendations produced from priority setting exercises. Authors of the priority setting exercises expressed a desire for increased uptake of the results of the priority setting exercises by funding agencies. Key barriers for uptake were identified as challenges in involving stakeholders and the general public for participation in the priority setting exercise.

Conclusions: Priority settings exercises are important efforts to guide nutrition research toward effective allocation of resources. However, there seems to be a limited consideration of these priority setting exercises in research papers.

\title{
Keywords
}

Priority setting, nutrition, research, citation analysis, research waste 


\section{Introduction}

Setting research priorities is a formal procedure to generate consensus between different stakeholders on research questions considered a priority for resources allocation (1). Research agendas are most effective when they are built on identified knowledge gaps, demands and are constructed using multi-stakeholder dialogues (2). However, there is no gold standard for priority setting exercises. To optimize the allocation of limited resources, a rational and transparent development of research priority questions and research agendas is key.

The increasing global prevalence of the triple burden of malnutrition (coexistence of under nutrition and over nutrition or other diet related non communicable diseases in the same population) poses new challenges on policy and funding mechanisms. Target 2.2 of the Sustainable Development Goals is to "end malnutrition in all its forms" (3). It is clear however, that the world is lagging behind in achieving the global targets for nutrition (4). Concerns about research waste, defined as research that ignores end users (policy makers, patients and practitioners) needs, and/ or is done in isolation of concurrent evidence, when setting research priorities have been raised (2). Governments and decision makers need to take accelerated action based on research evidence, including priority setting exercises, to make meaningful change to improve nutrition. A timely review of how the research agendas and priorities are being taken up in nutrition research publications can generate lessons learned for future endeavors or guide remediation where necessary.

A review of nutrition priority setting exercises in 2016 summarized the main characteristics of these exercises including the priority setting objective, who is represented and the number of experts represented, target audience, funding source and follow up of results (5). The review found that 27 priority setting exercises were conducted between 1994 and 2018 covering numerous nutritional problems (e.g. obesity, under nutrition, malnutrition), within different populations (e.g. children, elderly, minority), and at different locations (Canada, United States, Australia, and low-and-middle income countries).

To date, however, it remains unclear whether and how the priority setting efforts in nutrition have influenced research output and driven the wider research agenda. In the present study, we investigated the uptake of priority setting exercises by the research community through 
publications. First, a citation analysis of papers referring to a priority setting exercise was conducted, including in-depth content analysis of the citing papers to map the reasons for citation. For the purpose of this study, a priority setting exercise will be referred to as "priority setting paper" and a paper that cites a priority setting paper as "cite". Second, a feedback survey with first and last authors of the priority setting exercise papers was organized to understand authors' perceptions on the impact and satisfaction of their priority setting exercise.

\section{Methods}

Priority setting exercise mapping review

We have used the twenty-seven nutrition priority setting papers previously identified in a systematic mapping review (5). The mapping review was updated in 2019 and one extra priority setting exercise was added in 2018 (6) (see supplementary table 1). More than half of the priority setting exercises $(n=15,53.6 \%)$ did not describe follow-up activities of the proposed priorities and, of the 28 priority setting papers; five (17.9\%) did not report the source of funding.

\section{Citation analysis}

Research is cumulative in nature and typically builds on existing knowledge. A citation of a paper is considered as an index of the 'utility' and 'visibility' of a piece of research (7). We therefore assessed manuscripts that cited previous priority setting exercise papers. We used the results of the mapping review mentioned above for the citation analysis.

Three resources were identified as potential databases to conduct the citation analysis: Web of Science, Elsevier's' Scopus and Google scholar. Each database presented unique limitations and none satisfied all requirements $(8,9)$, Scopus contains a higher proportion of social sciences journals compared to Web of Science. $(8,9)$, thus, the citation analysis was carried out on 5 April 2019 using Elsevier's' Scopus database. Exclusion criteria for the citation analysis included priority setting exercises found in grey literature, as they are not indexed in any of the databases, one priority setting paper because it was not indexed in Scopus (10). One priority setting paper was excluded (11) on the grounds that the priority setting was not the main goal of the paper. For each cite that references a priority setting paper, we extracted the reason for citation. 
From the content of the cites, we extracted the reason for citing the priority setting paper, as illustrated in supplementary table 2. Next, we also identified self-citation, which is defined here as the involvement of any author from the priority setting paper in the citing paper (12).

For each priority setting paper, we extracted the journal name, year of publication, journal's impact factor, number of cites, and self-citations.

The relationships between the priority setting papers and between the priority setting papers and their correspondence cites were visualised as a network structure using the FruchtermanReingold algorithm in Gephi software (13). Gephi has been previously used to illustrate coauthorship on scientific publications (12). The Gephi figure was used to simplify the results table and illustrate the number of cites for each priority setting paper, the number of self-citations and the number of cites acting on the research questions identified as priorities. As well as the relationship between the priority setting exercises.

Both priority setting papers and cites were saved into an MS Excel spreadsheet in which each article was given a unique identifier. Each priority setting paper constituted a node, and each cite constituted an edge. We generated network views with the size of the node proportional to the number of citations. In order to differentiate cites that were original studies acting on the research questions identified as priorities, they were given a unique weight, which resulted in thicker edges in the network graph. Self-citations were indicated visually as dashed edges. Priority setting papers that worked on similar nutrition topics were given the same colour. Stata version 14.1 (StataCorp) was used to provide descriptive analysis for each priority setting paper, including number of cites, number of accessible cites, number of self-citations, and number of

cites for each reason of citation. Priority setting papers working on similar topics were given the same color of node. Blue nodes refer to priority setting papers working on obesity related topics, orange on meta-level research including methodological aspects of setting research priorities, grey on malnutrition in low-and middle-income countries, pink on priority setting exercises that link nutrition and mental health.

\section{Impact and satisfaction survey}

We administered a questionnaire among first and last authors of the 28 priority setting exercises that were included in the mapping review, the survey aimed to capture the priority setting authors' satisfaction with the priority setting exercise and their perception on whether the priority 
setting exercise had impact. The questionnaire (Annex 1) included the following five multiplechoice questions: Q1- Are you satisfied with the outcome and impact of the priority setting exercise? Q2- How would you estimate the impact of the priority setting exercise? Q3- Have the results of the priority setting exercise as recommended in your article been used by sponsors or grant organizations? Q4- Did your priority setting paper inform scholarly thinking in the domain, for example by influencing the choice of studied topics or the allocation of grants? Q5- Did you implement a strategy for the dissemination of the results other than publication? Q6- Do you have any recommendations to increase the impact of priority setting exercise? Voluntary openended question followed each multiple-choice question that allowed authors to explain their answer.

The choice of including the first and last author was based on the assumption that the first author led the work under the supervision of the principal investigator, who is often the last author (14). One email with an invitation to participate in the study and two reminders were sent over a period of 90 days. All authors were encouraged to suggest any other author or collaborator involved in the priority setting exercise that could provide valuable information. The email was sent to 52 researchers in total. Authors were asked to return an informed consent by email. In accordance to Belgian Law, the questionnaire did not need clearance from an ethics committee.

To extract results from the open-ended questions, answers were analysed qualitatively by DH and JER, answers were grouped in themes, and summarized and included as supplementary information.

\section{Results}

\section{Citation analysis}

For each priority setting paper, table 1 summarizes the publication year, impact factor of the journal, the total number of cites, the number of accessible cites and the number of cites per reason of citation.

We included 21 out of the 28 priority setting papers from the mapping review in the citation analysis. The 21 priority setting papers included had 435 cites, of which 338 could be accessed through our institutional subscription to journals. The excluded 97 cites were either not written in 
English, or duplicates, or grey literature i.e. not indexed, comments as letters to editors, books chapters.

Priority setting papers were carried out, between 1994 and 2018. Half of the priority setting papers were published by 2013, and 5 priority setting papers were published in 2016.

The median of the journal's impact factor for the priority setting is 4.021. It seems logical that papers in higher impact factor journals receive more citations, since impact factor is calculated based on the yearly average citation that articles published in a specific journal receive in the last two years. However, in our sample we conclude that the impact factor is not associated with the number of citations of the priority setting papers adjusting for the year of publication.

Among the accessible cites, a total of $60(17.8 \%)$ were self-citations, that either acknowledged the priority setting paper or cited it as background information (see supplementary table 2 for the explanation). On average, priority setting papers accumulated 18 cites, excluding self-citations. However, looking at the reasons for citations (supplementary table 2) Overall, only a small number $(8.3 \%, 28$ of 338$)$ of all cites referred to the priority setting paper to act on the priority setting papers proposed questions with a median of 1 cite $(\mathrm{QR}=0-1)$ per priority setting paper. Most $(64.2 \%, 217$ of 338) of the cites cited the priority setting exercise papers as background information or as previous knowledge to support evidence (an average 10.3 cites) (table 1).. A total of 78 cites $(23.1 \%, 78$ of 338) acknowledged the results of the priority setting paper without answering any of the proposed questions on the priority list. Only a small sample of cites (4.4\%, 15 of 338) referred to the priority setting papers as a reference to the methods used.

Figure 1 shows the relationship network between the priority setting papers and the cites. Nodes with the same colour refer to priority setting papers in the same domain. All priority setting papers that work on similar topics (as indicated by the same colour) have published their findings without referring to older priority setting exercises. Figure 1 also shows a total of 4 priority setting papers (15-18) were cited at least 4 times by cites acting on the proposed questions on the priority setting paper list. 
Table 1: Summary of citing papers and reason for priority setting exercise citation

\begin{tabular}{|c|c|c|c|c|c|c|c|c|c|c|c|}
\hline Priority Setting Papers & Journal & $\begin{array}{l}\text { Year of } \\
\text { publication }\end{array}$ & $\begin{array}{l}\text { Journal's } \\
\text { impact } \\
\text { factor }\end{array}$ & $\begin{array}{l}\text { \# Of } \\
\text { cites }\end{array}$ & $\begin{array}{l}\text { \# Of } \\
\text { eligible } \\
\text { cites }\end{array}$ & $\begin{array}{l}\text { \# Of } \\
\text { cites } \\
\text { acting } \\
\text { on the } \\
\text { priority } \\
\text { setting } \\
\text { exercis } \\
\text { e }\end{array}$ & $\begin{array}{l}\text { \# Of } \\
\text { self } \\
\text { citati } \\
\text { on }\end{array}$ & $\begin{array}{l}\# \text { Of } \\
\text { cites } \\
\text { using } \\
\text { the } \\
\text { same } \\
\text { meth } \\
\text { od }\end{array}$ & $\begin{array}{l}\text { \# Of cites } \\
\text { acknowle } \\
\text { dging the } \\
\text { priority } \\
\text { setting } \\
\text { exercise }\end{array}$ & $\begin{array}{l}\text { \# Of cites } \\
\text { referring to } \\
\text { backgroun } \\
\mathrm{d} \\
\text { informatio } \\
\mathrm{n} \text { and other } \\
\text { reasons }\end{array}$ & $\begin{array}{l}\text { \# Of citing } \\
\text { papers } \\
\text { excluding } \\
\text { self-citations }\end{array}$ \\
\hline $\begin{array}{l}\text { 20. Haddad et al: A new global } \\
\text { research agenda for food }\end{array}$ & Nature & 2016 & 43.070 & 31 & 25 & 1 & 1 & 0 & 9 & 15 & 30 \\
\hline $\begin{array}{l}\text { 5. Angood et al 1: Research } \\
\text { Priorities to Improve the } \\
\text { Management of Acute } \\
\text { Malnutrition in Infants Aged Less } \\
\text { Than Six Months (MAMI) }\end{array}$ & Plos Medicine & 2015 & 11.048 & 9 & 8 & 1 & 3 & 0 & 5 & 2 & 6 \\
\hline $\begin{array}{l}\text { 11. Lachat et al: Developing a } \\
\text { Sustainable Nutrition Research } \\
\text { Agenda in Sub-Saharan Africa- } \\
\text { Findings from the SUNRAY } \\
\text { Project }\end{array}$ & Plos Medicine & 2014 & 11.048 & 14 & 11 & 0 & 6 & 0 & 5 & 6 & 8 \\
\hline $\begin{array}{l}\text { 7. Buzzard \& Sievert: Research } \\
\text { priorities and recommendations } \\
\text { for dietary assessment } \\
\text { methodology }\end{array}$ & $\begin{array}{l}\text { The American } \\
\text { Journal of } \\
\text { Clinical } \\
\text { Nutrition }\end{array}$ & 1994 & 6.568 & 46 & 34 & 4 & 0 & 0 & 8 & 22 & 46 \\
\hline
\end{tabular}




\begin{tabular}{|c|c|c|c|c|c|c|c|c|c|c|c|}
\hline $\begin{array}{l}\text { 1. Aggett: Research Priorities in } \\
\text { Complementary Feeding: } \\
\text { International Paediatric } \\
\text { Association (IPA) and European } \\
\text { Society of Paediatric } \\
\text { Gastroenterology, Hepatology, } \\
\text { and Nutrition (ESPGHAN) } \\
\text { Workshop }\end{array}$ & Pediatrics & 2000 & 5.401 & 11 & 5 & 1 & 0 & 0 & 1 & 3 & 11 \\
\hline $\begin{array}{l}\text { 3. Alley et al: A Research } \\
\text { Agenda: The Changing } \\
\text { Relationship Between Body } \\
\text { Weight and Health in Aging }\end{array}$ & $\begin{array}{l}\text { Journal of } \\
\text { Gerontology }\end{array}$ & 2008 & 4.711 & 23 & 17 & 1 & 1 & 0 & 1 & 15 & 22 \\
\hline $\begin{array}{l}\text { 12. McKinnon et al: } \\
\text { Considerations for an Obesity } \\
\text { Policy Research Agenda }\end{array}$ & $\begin{array}{l}\text { American } \\
\text { Journal of } \\
\text { Preventive } \\
\text { Medicine }\end{array}$ & 2009 & 4.435 & 51 & 47 & 1 & 6 & 0 & 4 & 42 & 45 \\
\hline $\begin{array}{l}\text { 19. Pratt et al: Childhood Obesity } \\
\text { Prevention and Treatment } \\
\text { Recommendations for Future } \\
\text { Research }\end{array}$ & $\begin{array}{l}\text { American } \\
\text { Journal of } \\
\text { Preventive } \\
\text { Medicine }\end{array}$ & 2008 & 4.435 & 57 & 41 & 7 & 3 & 0 & 10 & 24 & 54 \\
\hline $\begin{array}{l}\text { 16. Ohlhorst et al: Nutrition } \\
\text { research to affect food and a } \\
\text { healthy life span }\end{array}$ & $\begin{array}{l}\text { The American } \\
\text { Society for } \\
\text { Nutrition }\end{array}$ & 2013 & 4.416 & 16 & 10 & 1 & 2 & 0 & 3 & 6 & 14 \\
\hline $\begin{array}{l}\text { 14. Menon et al: Strengthening } \\
\text { implementation and utilization of } \\
\text { nutrition interventions through } \\
\text { research: a framework and } \\
\text { research agenda }\end{array}$ & $\begin{array}{l}\text { Annals of The } \\
\text { New York } \\
\text { Academy of } \\
\text { Sciences } \\
\text { Issue: A } \\
\text { Global } \\
\text { Research } \\
\text { Agenda for } \\
\text { Nutrition } \\
\text { Science }\end{array}$ & 2014 & 4.295 & 23 & 19 & 0 & 5 & 0 & 5 & 14 & 18 \\
\hline
\end{tabular}




\begin{tabular}{|c|c|c|c|c|c|c|c|c|c|c|c|}
\hline $\begin{array}{l}\text { 15. Nagata et al: Research } \\
\text { Priorities for Eight Areas of } \\
\text { Adolescent Health in Low- and } \\
\text { Middle-Income Countries }\end{array}$ & $\begin{array}{l}\text { Journal of } \\
\text { Adolescent } \\
\text { Health }\end{array}$ & 2016 & 4.021 & 10 & 7 & 0 & 3 & 0 & 3 & 4 & 7 \\
\hline $\begin{array}{l}\text { 2. Kumanyika et al: Achieving } \\
\text { Healthy Weight in African- } \\
\text { American Communities: } \\
\text { Research Perspectives and } \\
\text { Priorities }\end{array}$ & $\begin{array}{l}\text { Obesity } \\
\text { research } \\
\text { Journal }\end{array}$ & 2005 & 3.969 & 48 & 35 & 4 & 7 & 0 & 6 & 25 & 41 \\
\hline $\begin{array}{l}\text { 8. Byrne et al: Identifying priority } \\
\text { areas for longitudinal research in } \\
\text { childhood obesity: Delphi } \\
\text { technique survey }\end{array}$ & $\begin{array}{l}\text { International } \\
\text { Journal of } \\
\text { Pediatric } \\
\text { Obesity }\end{array}$ & 2008 & 3.713 & 16 & 11 & 1 & 1 & 7 & 1 & 2 & 15 \\
\hline $\begin{array}{l}\text { 9. Curtin,et al. The healthy } \\
\text { weight research network: a } \\
\text { research agenda to promote } \\
\text { healthy weight among youth with } \\
\text { autism spectrum disorder and } \\
\text { other developmental disabilities }\end{array}$ & $\begin{array}{l}\text { World } \\
\text { Obesity. } \\
\text { Pediatric } \\
\text { Obesity }\end{array}$ & 2017 & 3.713 & 2 & 1 & 0 & 0 & 0 & 1 & 0 & 2 \\
\hline $\begin{array}{l}\text { 10. D'ANDREAMATTEO,et al. } \\
\text { Defining Research Priorities for } \\
\text { Nutrition and Mental Health: } \\
\text { Insights from Dietetics Practice }\end{array}$ & $\begin{array}{l}\text { Perspectives } \\
\text { in practice }\end{array}$ & 2016 & 3.713 & 1 & 0 & 0 & 0 & 0 & 0 & 0 & 1 \\
\hline $\begin{array}{l}\text { 21. Masters et al: Priority } \\
\text { interventions to improve maternal } \\
\text { and child diets in Sub-Saharan } \\
\text { Africa and South Asia }\end{array}$ & $\begin{array}{l}\text { Maternal and } \\
\text { child nutrition }\end{array}$ & 2018 & 3.305 & 4 & 4 & 0 & 1 & 0 & 2 & 2 & 3 \\
\hline $\begin{array}{l}\text { 4. Angood et al: Research } \\
\text { Priorities on the Relationship } \\
\text { between Wasting and Stunting }\end{array}$ & Plos One & 2016 & 2.776 & 13 & 12 & 1 & 5 & 1 & 3 & 7 & 8 \\
\hline
\end{tabular}




\begin{tabular}{|c|c|c|c|c|c|c|c|c|c|c|c|}
\hline $\begin{array}{l}\text { 6. Brown et al: Setting priorities } \\
\text { for zinc-related health research to } \\
\text { reduce children's disease burden } \\
\text { worldwide: an application of the } \\
\text { Child Health and Nutrition } \\
\text { Research Initiative's research } \\
\text { priority-setting method }\end{array}$ & $\begin{array}{l}\text { Public Health } \\
\text { Nutrition }\end{array}$ & 2009 & 2.526 & 17 & 15 & 0 & 7 & 6 & 1 & 8 & 10 \\
\hline $\begin{array}{l}\text { 13. McPherson et al: A Call to } \\
\text { Action: Setting the Research } \\
\text { Agenda for Addressing Obesity } \\
\text { and Weight-Related Topics in } \\
\text { Children with Physical } \\
\text { Disabilities }\end{array}$ & $\begin{array}{l}\text { Childhood } \\
\text { Obesity }\end{array}$ & 2016 & 2.426 & 6 & 4 & 0 & 1 & 0 & 2 & 2 & 5 \\
\hline $\begin{array}{l}\text { 18. Ward et al: Expert and } \\
\text { Stakeholder Consensus on } \\
\text { Priorities for Obesity Prevention } \\
\text { Research in Early Care and } \\
\text { Education Settings }\end{array}$ & $\begin{array}{l}\text { Childhood } \\
\text { Obesity }\end{array}$ & 2013 & 2.426 & 20 & 18 & 5 & 4 & 0 & 2 & 11 & 16 \\
\hline $\begin{array}{l}\text { 17. Ramirez et al: Salud } \\
\text { America! Developing a National } \\
\text { Latino Childhood Obesity } \\
\text { Research Agenda }\end{array}$ & $\begin{array}{l}\text { Health } \\
\text { Education \& } \\
\text { Behavior }\end{array}$ & 2011 & 2.190 & 17 & 14 & 0 & 4 & 1 & 6 & 7 & 13 \\
\hline Total & & & & 435 & 338 & 28 & 60 & 15 & 78 & 217 & 375 \\
\hline Median & & 2013 & 4.021 & 16 & 12 & 1 & 3 & 0 & 3 & 7 & 13 \\
\hline Mean & & & & 20.7 & 16.1 & 1.3 & 2.9 & 0.7 & 3.7 & 10.3 & 17,9 \\
\hline
\end{tabular}




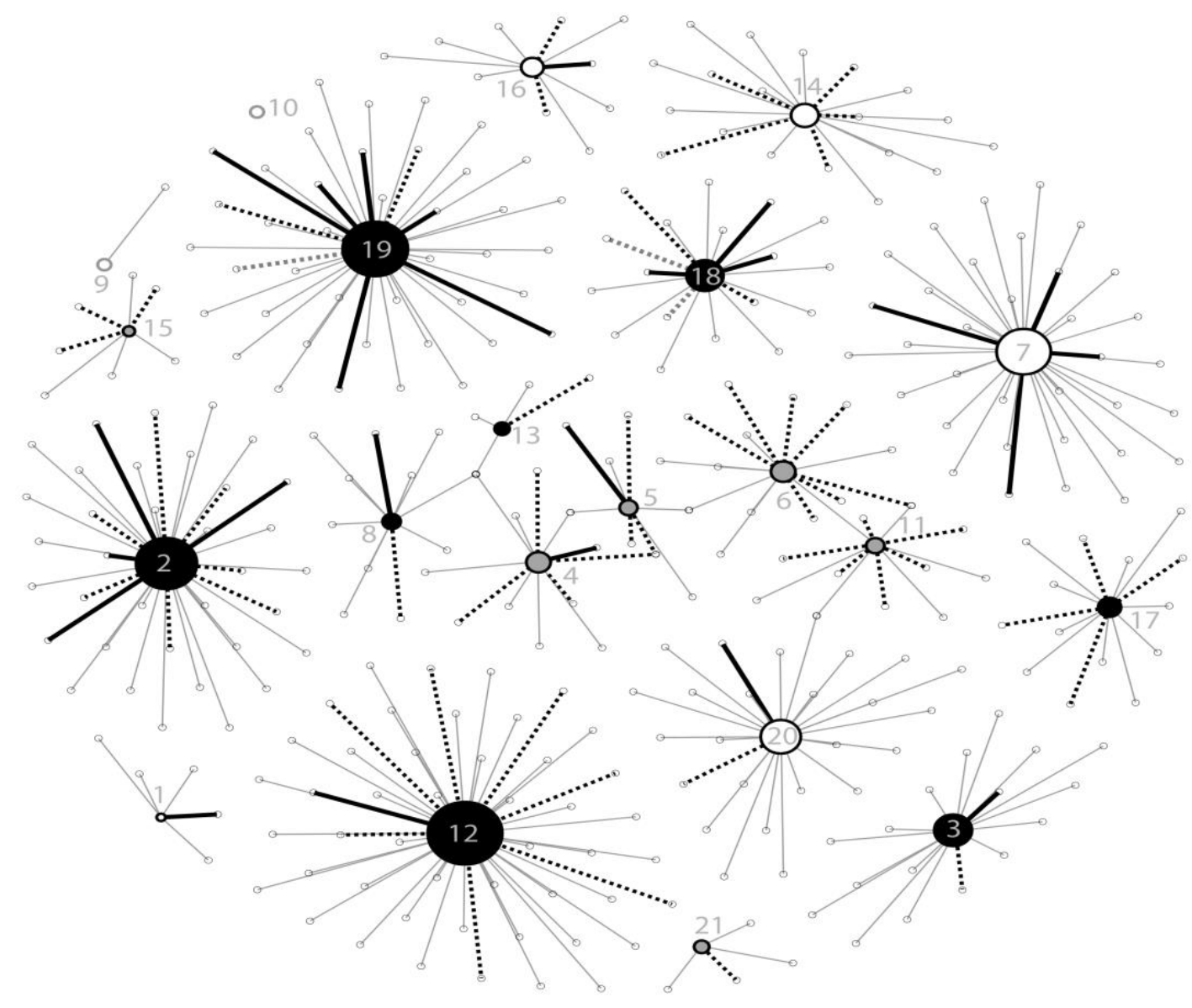

Figure 1 Citation analysis network

Numbers refer to the priority setting research papers 1(19), 2(17), 3(20), 4(21), 5(22), 6(23), 7(18), 8(24), 9 (25), 10(26), 11(27), 12(28), 13(29), 14(30), 15(31), 16(32), 17(33),18 (16), 19 (15), 20 (34) 21(6) Thick lines refer to self-citation of the priority setting. Dashed lines refer to citing papers acting the priority setting. Black nodes refer to priority setting papers working on obesity related topics, white on global topics, grey on malnutrition in low-and middle-income countries, grey border on nutrition and mental health 


\section{Impact and satisfaction survey.}

Of the 52 priority setting paper authors that were contacted, 23 responses were received (44\% response rate). After removing duplicates (9\%, 2 of 23), and answers provided without completion of the informed consent (13\%, 3 of 23), 18 responses were included representing 14 priority setting papers $(6,16,17,19,21,25,26,31,32,34-37)$ (4 priority settings papers had 2 authors' input: $(21,22,26,27,35)$. Half the authors were satisfied with the outcome and impact of the priority setting exercise $(50 \%, 9$ of 18) (Table 2), with most (94\%, 17 of 18) estimating the impact as intermediate and higher. Only 2 authors reported that the results from the priority setting exercise had not been used by any funding agency. The majority (83\%, 15 of 18) reported that the priority setting exercise informed scholarly thinking in the domain

Respondents that were 'more-or-less', or 'not satisfied' with the impact of the priority setting exercise $(n=7)$ expressed a desire for higher uptake of the recommendations of the priority setting exercise by funding agencies. Authors found it challenging to reach out to stakeholders and involve citizens during the priority setting exercise, which was considered to be a driver for the lack of uptake, expressed well by one author "We had difficulty reaching out to the general community and getting input, esp. from diverse/different participants." A summarized table of the themes that emerged from the open-ended questions are included as supplementary information and supplementary figure 1.

Most authors (72\%, 13 of 18) implemented a dissemination strategy through conferences, workshops, emails to stakeholders, social media posts, websites, and publications. Two authors explained that there was insufficient funding to disseminate further or that dissemination was not considered part of their priority setting exercise work.

To increase impact, authors suggested the need to involve funding agency and implementing stakeholders, including governments, and end-users (i.e. patients, practitioners and policy makers) from the beginning $(n=4)$ and to engaged in additional dissemination activities beyond publishing the priority setting exercise article in a scientific journal, e.g. networking, stakeholder endorsement and advocacy for the priority setting exercise in conferences that bring together researchers and funders $(n=11)$. Authors also expressed that as priority setters, they need to 
earmark sufficient funds to act on the proposed questions on the priority list. Finally, one expressed the need for a clear a priori purpose $(n=1)$.

Table 2: Summary of responses of priority setting exercises' authors (5 questions, 18 responses)

\begin{tabular}{|c|c|}
\hline Question & Number of responses and percentage* \\
\hline \multicolumn{2}{|c|}{ Q1 Are you satisfied with the outcome and impact of the priority setting exercise? } \\
\hline Yes & $9(50 \%)$ \\
\hline More or Less & $7(39 \%)$ \\
\hline No & $2(11 \%)$ \\
\hline \multicolumn{2}{|c|}{ Q2 How would you estimate the impact of the priority setting exercise? } \\
\hline Low & $1(6 \%)$ \\
\hline Intermediate & $10(55 . \%)$ \\
\hline High & $6(33 \%)$ \\
\hline Very high & $1(6 \%)$ \\
\hline \multicolumn{2}{|c|}{$\begin{array}{l}\text { Q3 Have the results of the priorities set recommended in your article been used by } \\
\text { sponsors or grant organizations?** }\end{array}$} \\
\hline Yes & $8(44 \%)$ \\
\hline Maybe & $8(44 \%)$ \\
\hline No & $2(12 \%)$ \\
\hline \multicolumn{2}{|c|}{$\begin{array}{l}\text { Q4 Did your paper inform scholarly thinking in the domain, for example by } \\
\text { influencing the choice of studied topics or the allocation of grants }\end{array}$} \\
\hline Yes & $15(83 \%)$ \\
\hline No & $3(17 \%)$ \\
\hline \multicolumn{2}{|c|}{$\begin{array}{l}\text { Q5 Did you implement a strategy for the dissemination of the results other than } \\
\text { publication? }\end{array}$} \\
\hline Yes & $13(76 \%)$ \\
\hline
\end{tabular}


\begin{tabular}{|l|l|}
\hline No & $5(24 \%)$ \\
\hline
\end{tabular}

*Total number of responses $=18 * * \mathrm{Q} 3$ is the only question with a "maybe" option

\section{Discussion}

We aimed to gain deeper understanding on how research priorities were considered and used to shape the nutrition research agenda through publications. Although half of the priority setting exercises' authors were positive about their priority setting exercise impact, our results show that priority setting exercises are rarely cited for the purpose of acting on the proposed research priorities, but more commonly to provide background information or evidence on a topic. Moreover, different groups that work on priority setting exercises on similar nutrition topics have published their findings without referring to previously published priority setting exercises. Although authors of priority setting exercises perceive the exercise as important; they call for stronger uptake of the results by funders in order to drive the research agenda

An optimal research cycle considers the needs of all possible users of the research output (including patients, practitioners and policy makers), together with the existing available evidence in order to reduce research waste and maximise public return on investment (2). The present analysis points towards two missing links in the research cycle related to nutrition. Primarily, research questions from priority setting exercises papers are rarely acted upon in cited publications, potentially indicating poor follow-up in research practice. When funding priority setting exercises, it seems logical that donors also earmark funding and organize a call for research that is specifically geared to address the prioritized questions, however this seems to rarely happen. Early engagement of funders and guided discussion between funders, researchers and other stakeholders at the beginning of the priority setting exercises could possibly increase uptake of priority setting exercises recommendations (5). Such a process would contribute to enhancing the value of research and avoid the allocation of resources to efforts that do not address key priorities.

The second missing link is observed between different priority setting exercise efforts that work on a similar topic e.g. obesity, malnutrition in low-and middle-income countries, nutrition and mental health etc. as they often did not acknowledge or reference the priority setting exercises done prior. We acknowledge that priority setting exercises included in this study were done at 
different moments, often years apart. However, the results of previous priority setting exercises are apparently poorly considered by authors involved in setting priorities on the same topic. Knowledge transfer between different groups could increase the value of the priority setting exercises and enlarge the scope of the priority setting results application. Further research to understand the reasons for the lack of referencing the prior priority setting exercises is recommended.

The results from the priority setting exercises authors' survey on increasing impact of priority setting in nutrition research through the involvement of funding agency and implementing stakeholders, and the challenge of involve the public, feeds in the debate of whether researchers are the most eligible to lead priority setting exercises. It is clear that there is a need to foster bottom-up approaches where priority setting exercises are led by citizens and affected members of the society instead of academics (38). It is also important to increase the awareness around the priority settings exercises regardless which journal they published and the significance of their uptake, specifically to act upon the proposed urgent questions. Therefore, we have created and online repository to centralize the retrieved priority setting exercises in nutrition research, in an attempt to increase their relevance and use (39).

We acknowledge that the assessment of the uptake and impact of priority setting exercises is challenging. Whilst citation analysis is a method that has been used before to assess impact (7), the citation analysis and priority setting papers' author impact and satisfaction survey provide insight into only one aspect of assessing research impact. The influence of nutrition research priority setting exercise likely extends beyond being included as a citation in literature. More measures to assess impact should be put in place (40) including assessment of advancement of knowledge, legislation and policy, economic benefits, community benefits. It is possible that the dissemination activities implemented by researchers after the priority setting exercise led to nudging of academic's thinking around the topic, and triggering responses to some proposed priority setting exercises were actioned without necessarily citing them.

Editorial boards of scientific journals are important stakeholders to engage during the dissemination of priority setting exercises recommendations. Providing a clear justification of the added value of new nutrition research efforts is essential and editorial boards can be instrumental to guide researchers in this regard (2). Editorial boards typically request authors to describe 
added value of newly submitted paper in the instructions for authors. Such justification may include use of systematic reviews of what is already known, but also recommendations for research from priority setting efforts. In addition to publishing of priority setting exercises manuscripts, editorial boards should engage actively and organise additional efforts to follow-up on the recommendations are required, i.e. through a call for papers addressing the proposed priorities.

Finally, with increased burden of malnutrition on global health, there is an urgent need to set clear and transparent priorities for action in nutrition. The Sustainable Development Goals (SDGs) (3) and the UN Decade of Action on Nutrition (2016-2025) are windows of opportunity for concerted action on nutrition and nutrition research. The present findings however, indicate that specific measures including efforts to ensure priority setting exercises are not conducted in isolation from related efforts, stakeholders are integrated into priority setting exercise from the beginning, more effective dissemination strategies are implemented and donors earmark funds that allow for action on the priorities. are still needed to ensure that nutrition priority setting exercises are taken up and responded to in future nutrition research agendas concerted efforts are needed to involve stakeholders (in particular non-researchers and funders) during the process.

\section{References}

1. Viergever RF, Olifson S, Ghaffar A, Terry RF. A checklist for health research priority setting: nine common themes of good practice. Health Res Policy Syst. 2010;8:36.

2. Chalmers I, Bracken MB, Djulbegovic B, Garattini S, Grant J, Guelmezoglu AM, et al. How to increase value and reduce waste when research priorities are set. Lancet. 2014;383(9912):156-65.

3. Development Initiatives Global Nutrition Report 2017: Nourishing the SDGs. Bristol, UK: Development Initiatives; 2017.

4. Development Initiatives Global Nutrition Report : Shining a light to spur action on nutrition 2018.

5. Hawwash D, Pinxten W, Bonn NA, Verstraeten R, Kolsteren P, Lachat C. Perspective: Consideration of Values When Setting Priorities in Nutrition Research: Guidance for Transparency. Adv Nutr. 2018;9(6):671-87.

6. Masters WA, Rosettie K, Kranz S, Pedersen SH, Webb P, Danaei G, et al. Priority interventions to improve maternal and child diets in Sub-Saharan Africa and South Asia. Matern Child Nutr. 2018;14(2):e12526.

7. Guthrie S, Bienkowska-Gibbs T, Manville C, Pollitt A, Kirtley A, Wooding S. The impact of the National Institute for Health Research Health Technology Assessment 
programme, 2003-13: a multimethod evaluation. Health Technol Assess. 2015;19(67):1291.

8. Bakkalbasi N, Bauer K, Glover J, Wang L. Three options for citation tracking: Google Scholar, Scopus and Web of Science. Biomed Digit Libr. 2006;3:7.

9. Martín-Martín A, Orduna-Malea E, Thelwall M, Delgado López-Cózar E. Google Scholar, Web of Science, and Scopus: A systematic comparison of citations in 252 subject categories. Journal of Informetrics. 2018;12(4):1160-77.

10. Wu Y, Lau B, Bleich S, Cheskin L, Boult C, Segal J, et al. Future Research Needs for Childhood Obesity Prevention Programs. The Johns Hopkins University Evidence-based Practice Center; 2013.

11. Black RE, Victora CG, Walker SP, Bhutta ZA, Christian P, de Onis M, et al. Maternal and child undernutrition and overweight in low-income and middle-income countries. Lancet. 2013;382(9890):427-51.

12. Lachat C, Roberfroid D, Van den Broeck L, Van den Briel N, Nago E, Kruger A, et al. A decade of nutrition research in Africa: assessment of the evidence base and academic collaboration. Public Health Nutr. 2015;18(10):1890-7.

13. Bastian M, Heymann S, Jacomy M. Gephi : An Open Source Software for Exploring and Manipulating Networks 2009 [Available from: https://gephi.org/publications/gephi-bastianfeb09.pdf.

14. Zhao DZ, Strotmann A. Counting First, Last, or All Authors in Citation Analysis: A Comprehensive Comparison in the Highly Collaborative Stem Cell Research Field. J Am Soc Inf Sci Tec. 2011;62(4):654-76.

15. Pratt CA, Stevens J, Daniels S. Childhood obesity prevention and treatment: recommendations for future research. Am J Prev Med. 2008;35(3):249-52.

16. Ward DS, Vaughn A, Story M. Expert and stakeholder consensus on priorities for obesity prevention research in early care and education settings. Child Obes. 2013;9(2):116-24.

17. Kumanyika SK, Gary TL, Lancaster KJ, Samuel-Hodge CD, Banks-Wallace J, Beech BM, et al. Achieving healthy weight in African-American communities: research perspectives and priorities. Obes Res. 2005;13(12):2037-47.

18. Buzzard IM, Sievert YA. Research priorities and recommendations for dietary assessment methodology. First International Conference on Dietary Assessment Methods. Am J Clin Nutr. 1994;59(1 Suppl):275S-80S.

19. Aggett PJ. Research priorities in complementary feeding: International Paediatric Association (IPA) and European Society of Paediatric Gastroenterology, Hepatology, and Nutrition (ESPGHAN) workshop. Pediatrics. 2000;106(5):1271.

20. Alley DE, Ferrucci L, Barbagallo M, Studenski SA, Harris TB. A Research Agenda: The Changing Relationship Between Body Weight and Health in Aging. J Gerontol a-Biol. 2008;63(11):1257-9.

21. Angood C, Khara T, Dolan C, Berkley JA, WaSt Technical Interest G. Research Priorities on the Relationship between Wasting and Stunting. PLoS One. 2016;11(5):e0153221.

22. Angood C, McGrath M, Mehta S, Mwangome M, Lung'aho M, Roberfroid D, et al. Research priorities to improve the management of acute malnutrition in infants aged less than six months (MAMI). PLoS Med. 2015;12(4):e1001812. 
23. Brown KH, Hess SY, Boy E, Gibson RS, Horton S, Osendarp SJ, et al. Setting priorities for zinc-related health research to reduce children's disease burden worldwide: an application of the Child Health and Nutrition Research Initiative's research priority-setting method. Public Health Nutr. 2009;12(3):389-96.

24. Byrne S, Wake M, Blumberg D, Dibley M. Identifying priority areas for longitudinal research in childhood obesity: Delphi technique survey. Int J Pediatr Obes. 2008;3(2):1202.

25. Curtin C, Must A, Phillips S, Bandini L. The healthy weight research network: a research agenda to promote healthy weight among youth with autism spectrum disorder and other developmental disabilities. Pediatr Obes. 2017;12(1):e6-e9.

26. D'Andreamatteo C, Davison KM, Vanderkooy P. Defining Research Priorities for Nutrition and Mental Health: Insights from Dietetics Practice. Can J Diet Pract Res. 2016;77(1):35-42.

27. Lachat C, Nago E, Roberfroid D, Holdsworth M, Smit K, Kinabo J, et al. Developing a sustainable nutrition research agenda in sub-Saharan Africa--findings from the SUNRAY project. PLoS Med. 2014;11(1):e1001593.

28. McKinnon RA, Orleans CT, Kumanyika SK, Haire-Joshu D, Krebs-Smith SM, Finkelstein EA, et al. Considerations for an obesity policy research agenda. Am J Prev Med. 2009;36(4):351-7.

29. McPherson AC, Ball GD, Maltais DB, Swift JA, Cairney J, Knibbe TJ, et al. A Call to Action: Setting the Research Agenda for Addressing Obesity and Weight-Related Topics in Children with Physical Disabilities. Child Obes. 2016;12(1):59-69.

30. Menon P, Covic NM, Harrigan PB, Horton SE, Kazi NM, Lamstein S, et al.

Strengthening implementation and utilization of nutrition interventions through research: a framework and research agenda. Ann Ny Acad Sci. 2014;1332:39-59.

31. Nagata JM, Ferguson BJ, Ross DA. Research Priorities for Eight Areas of Adolescent Health in Low- and Middle-Income Countries. J Adolesc Health. 2016;59(1):50-60.

32. Ohlhorst SD, Russell R, Bier D, Klurfeld DM, Li Z, Mein JR, et al. Nutrition research to affect food and a healthy life span. Am J Clin Nutr. 2013;98(2):620-5.

33. Ramirez AG, Chalela P, Gallion KJ, Green LW, Ottoson J. Salud America! Developing a National Latino Childhood Obesity Research Agenda. Health Educ Behav. 2011;38(3):25160 .

34. Haddad L, Hawkes C, Webb P, Thomas S, Beddington J, Waage J, et al. A new global research agenda for food. Nature. 2016;540(7631):30-2.

35. Angood C, McGrath M, Mehta S, Mwangome M, Lung'aho M, Roberfroid D, et al. Research Priorities to Improve the Management of Acute Malnutrition in Infants Aged Less Than Six Months (MAMI). Plos Medicine. 2015;12(4).

36. UNSCN. UNITED NATIONS GLOBAL NUTRITION AGENDA (UNGNA v. 1.0). 2015.

37. Bill and Melinda Gates Foundation, UK Aid. Agriculture for Improved Nutrition: A Future Research Agenda. 2017.

38. James Lind Alliance [cited 2019 13th August ]. Available from: http://www.jla.nihr.ac.uk.

39. Ghent University. Better Nutrition Research- Research Priorities 2020 [Available from: https://betternutritionresearch.ugent.be/research-priorities.

40. Sarli CC, Dubinsky EK, Holmes KL. Beyond citation analysis: a model for assessment of research impact. J Med Libr Assoc. 2010;98(1):17-23. 
